\title{
A Comparison of Convergence Angles of Crown preparations in an undergraduate programme at a Tertiary Institution
}

SADJ November 2021, Vol. 76 No. 10 p602- p606

N Naidoo', PD Moipolai², PD Motloba ${ }^{3}$

\begin{abstract}
Introduction

The retention of indirect dental restorations is of concern for clinicians as it influences the success of clinical outcomes. Retention and resistance are dependent on many factors including the convergence angles of the opposing axial wall tapers. Adequate axial wall taper is important in crown preparation to improve physical retention and increase resistance of the restoration.
\end{abstract}

\section{Aims and objectives}

To determine and compare the convergence angles (CA) of $\mathrm{KaVo}^{\circledR}$ teeth prepared for full coverage crown restorations by fourth year dental students in a preclinical fixed prosthodontics module in a five year dentistry training programme.

\section{Methodology}

Crown preparations produced by fourth year dental students at Sefako Makgatho Health Sciences University (SMU), South Africa, over a period of 3 years were included in this study. These preparations were digitally captured using CAD-CAM imaging technology. The images were analysed in Image ${ }^{\circledR}$ software to determine the mesio-distal convergence angles. Statistical analysis was undertaken using SPSS ver. 27 for Windows.

Results

The overall mean convergence angle of $15.38^{\circ} \pm 6.68^{\circ}$ was computed for $\mathrm{n}=75$ crown preparations. ANOVA revealed

\footnotetext{
Author affiliations:

1. Dr Naiesh Naidoo: BChD (UWC), PDD (Implantology) (UWC), Dip. Odont (Endodontics) (UP), Registrar in Prosthodontics, Department of Prosthodontics, School of Oral Health Sciences, Sefako Makgatho Health Sciences University (SMU), ORCID Number: 0000-0001- 7778-4104

2. Prof PD Moipolai: BChD (Leeds, UK), MDent (Pros)(Wits), MEd Wits). Head of Department - Prosthodontics, SMU. ORCID Number: 0000-0003-0388-5898

3. Prof PD Motloba: MDent (Comm Dent) (Medunsa), MBL (UNISA) Head of Department - Community Dentistry, SMU., ORCID Number: 0000-0003-1379-7576

Corresponding author:

Dr N Naidoo: Department of Prosthodontics, School of Oral Health Sciences, Sefako Makgatho Health Sciences University.

Email: naiesh@me.com

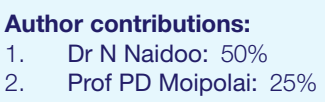

a significant difference $(\mathrm{p}<0.05)$ in the CA among the three cohorts (2017: $16.87^{\circ} \pm 6.94^{\circ} ; 2018: 17.23^{\circ} \pm 6.13^{\circ} ; 2019$ : $\left.12.02^{\circ} \pm 5.86^{\circ}\right)$. A reasonable proportion of dental students $n=25(33 \%)$ achieved the recommended CA of $6^{\circ}$ to $12^{\circ}$.

\section{Conclusion}

This study indicates that with objective evaluation tools, it is possible to improve on the intended guidelines for crown preparations during undergraduate teaching and training in pre-clinical Fixed Prosthodontics.

\section{Keywords}

Convergence angles, full coverage crown preparation; dental students, preclinical prosthodontics

\section{INTRODUCTION}

The concept of retention and resistance form is of vital clinical concern because of the vectoring of occlusal forces that may be directed in both a lateral and/or apical directions during oral functioning. ${ }^{1}$ Retention is the ability of a restoration to withstand removal forces along the long axis. $^{2}$ The term resistance form refers to the features of a tooth preparation that enhances the stability and durability of a restoration that affords it to resist dislodgment along an axis other than the path of placement. ${ }^{3}$ The angle formed by the intersection of the mesial and distal axial wall tapers is routinely referred to as the convergence angle (CA) of a tooth preparation, and is the measurement of the combined taper of opposing axial walls.

The underlying tooth preparation geometry necessitates precise application of these design features through specific preparation guidelines. Retention and resistance are interrelated and inseparable design qualities that need to be integrated synergistically through meticulous tooth preparation design. ${ }^{4}$ Retention and resistance dependent factors related to tooth preparation for full coverage restorations (FCR), include ensuring maximal cervical-occlusal height, appropriate surface texture of the preparation and most importantly, an acceptable CA. ${ }^{4,5}$ It is generally recognised that the smaller the convergence angle, the better the retention, and therefore, the greater longevity of the restoration. ${ }^{6}$

Adequate taper compensates for inaccuracies that may occur in the laboratory fabrication and processing of the restoration, as well as permitting a more favourable path of insertion. ${ }^{4}$ However, excessive taper often results in reduced 
retention, ${ }^{2}$ cement failure ${ }^{7}$ and pulp devitalisation. ${ }^{8}$ Whereas, inadequate taper compromises the structural durability of the restoration, aesthetics and the patient's existing occlusion. ${ }^{9}$ The shorter the preparation height, the more critical it becomes to limit the taper in order to increase the resistance against axial displacement. During undergraduate teaching and training of fixed prosthodontic principles, students' are taught the deleterious effects that over-preparation, underpreparation, increased axial wall inclination and reduced cervical-occlusal height can have on the health of the tooth, as well as, on the longevity of the restoration. Theoretically recommended guidelines advocate that tooth preparation walls be as close to parallel as possible, but still incorporate a slight taper, ideally, of between $4^{\circ}$ to $6^{\circ}$ with a recommended range of $3^{\circ}-14^{\circ}$ regarded as acceptable..$^{4,5,10}$

These guidelines were correlated with experimental studies conducted by Jørgensen ${ }^{11}$ Kaufman $^{12}$ and Wilson and Chan ${ }^{6}$ who showed that an inverse relationship exists between retention and taper. However, there is inconsistency in the degree of taper required for maximum retention. Theoretically, ideal taper should range from $4^{\circ}$ to $6^{\circ}$, but this is difficult to achieve clinically without creating undercuts on the preparation..$^{4,13,14}$ This translates to an ideal recommended CA of between $8^{\circ}$ and $12^{\circ}$. Effective taper criteria in a clinical milieu must be defined as a realistic and measurable goal that can be visualised and is readily repeatable and achievable. ${ }^{13,15}$

Full coverage restorations are often recommended for the restoration of extensively damaged and endodontically treated teeth. The ability of dentists to adequately prepare and assess the preparation for optimal retention and resistance is fundamental to the success of full coverage restorations. In the undergraduate pre-clinical Fixed Prosthodontics module at School of Oral Health Sciences, Sefako Makgatho Health Sciences University, the concept of axial wall taper is taught as per the prescribed guidelines. ${ }^{4}$ The rationale for this study was to determine; compare and evaluate the CA for teeth prepared for an anterior all-ceramic FCR by fourth year undergraduate dental students, against recommended guidelines.

\section{MATERIALS AND METHODS \\ Study design}

A descriptive cross-sectional study design was employed in this research.

\section{Study population}

The study population consisted of all ceramic anterior full coverage crown preparations prepared by cohorts of fourth year dental students during the 2017 to 2019 academic years. The crown preparations were included in the study, if they were prepared on maxillary central incisors 11, 21 and satisfied all the assessment requirements for crown preparation. The approval to undertake this study was granted by the SMU Ethics Committee.

These preparations were analysed using computer-aided design (CAD) technology to determine the CA for FCR prepared on maxillary central incisors 11,21 on a $\mathrm{KaVo}^{\circledR}$ typodont housed within a KaVo ${ }^{\circledR}$ dental patient simulation unit in a simulation laboratory. Eighty seven samples were included for the study that met the pass criteria for the module.
Figure 1: Sirona inEos $X 5^{\circledR}$ desktop model scanner

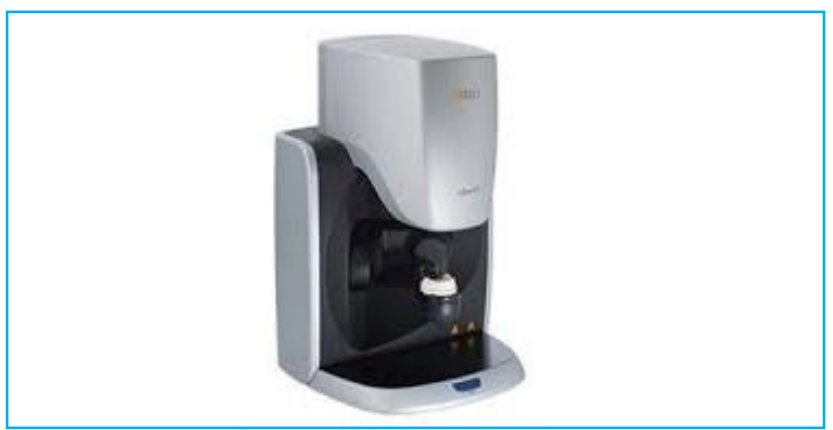

Preparation of the $\mathrm{KaVo}^{\circledR}$ model for digital assessment The individual tooth preparations were seated into a new maxillary $\mathrm{KaVO}^{\circledR}$ model before being digitally scanned for CA assessment. Prior to scanning, a $10 \mathrm{~mm}$ reference line was demarcated using a pair of dividers and then plotted using a $0.6 \mathrm{~mm}$ medium fine liner ink marker (Artline ${ }^{\circledR} 210$ ), on the $\mathrm{KaVo}^{\circledR}$ model base, below tooth 11. This served to allow digital calibration by the Image ${ }^{\circledR}$ computer software system, (National Institutes of health, Bethesda, MA, USA) prior to convergence angle calculation.

\section{Preparation for digital scanning}

All prepared surfaces of the crown preparation were surface treated with $\mathrm{CEREC}^{\circledR}$ Optispray (DentsplySirona) to enhance reflectability. This was done to allow accurate image acquisition of the digital impressions. The study utilised a Sirona inEos $X 5^{\circledR}$ desktop model scanner (DentsplySirona) (Figure 1) which allowed for five axis $\mathrm{KaVo}^{\circledR}$ model rotation to produce an accurate 3 dimensional (3D) rendering of the $\mathrm{KaVo}^{\circledR}$ model base and tooth preparation. The tooth preparation together with the model base were magnetically secured to the ground plate of the articulating scanning arm, which was reset before each scan, to ensure standardised image acquisition. A 3D digital scan of the tooth preparation was acquired and visually rendered on the Sirona InLab ${ }^{\circledR}$ (DentsplySirona) CAD software (v18.0) (Figure 2). Using the Sirona InLab ${ }^{\circledR} C A D$ software (DentsplySirona), the image was orientated in the standard frontal view. A screen shot of the image was then captured and imported into Microsoft ${ }^{\circledR}$ Paint application and saved as a Portable Network Graphic (PNG) file according to the allocated specimen number.

Assigning the critical point for convergence angle measurement

The saved image was imported into the Image ${ }^{\circledR}$ computer software system and calibrated using the plotted reference

Figure 2: Three dimensional rendering of the $\mathrm{KaVo}^{\circledR}$ model base and tooth preparation

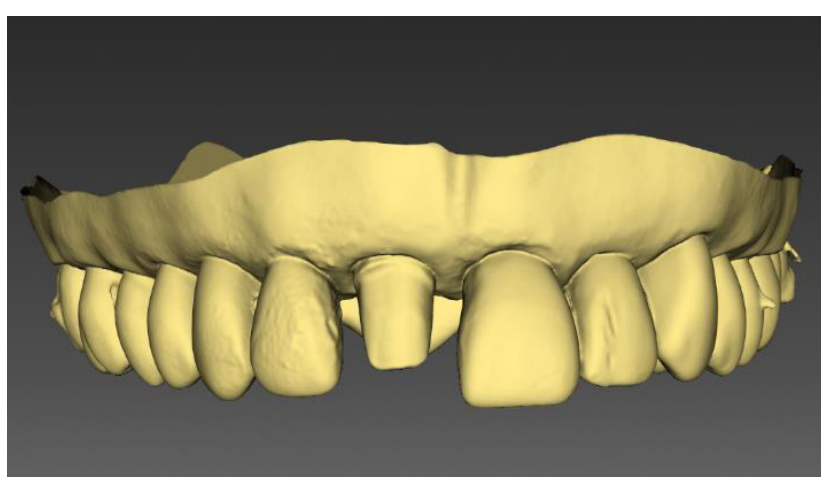


line. The angle calculation tool in the Image ${ }^{\circledR}$ software was used to calculate the inciso-axial angle $\left(\mathrm{b} 1^{\circ}\right.$ and $\left.\mathrm{c} 1^{\circ}\right)$ of the mesial and distal aspects of the tooth preparation. (Figure 3). The angle calculation software used plotted tangents to the axial preparation wall (ab and dc) and a tangent to incisal reduction preparation (bc), to calculate angles $\mathrm{b} 1^{\circ}$ and $c 1^{\circ}$ (Figure 3). For each sample, angles $\mathrm{b} 1^{\circ}$ and $\mathrm{c} 1^{\circ}$ were determined three times and the average value recorded for each side.

\section{Computation of convergence angle software}

Six measurements ( 3 mesial and 3 distal) for each sample were recorded on Microsoft ${ }^{\circledR}$ Excel $^{\circledR}$ spreadsheet for analysis. To compute inter and intra-rater reliability, five specimens from each cohort, were randomly selected by an independent person and re-assessed by the primary researcher and a co-supervisor. The convergence angle $x^{\circ}$ (Figure 3) was calculated using the mathematical equation:

$$
x^{\circ}=-180-\left[\left(180-b 1^{\circ}\right)+\left(180-c 1^{\circ}\right)\right]
$$

The equation utilised the Straight Line Theorem and Sum of Angles of a Triangle to calculate the convergence angle $x^{\circ}$ of the mesial and distal axial wall preparations.

\section{Results}

Eighty seven all ceramic FCR were distributed according to these cohorts: 2017 and 2018 ( $\mathrm{n}=30$ ) and 2019 ( $\mathrm{n}=$ 27). Further exclusion of samples was applied to ineligible preparations that exceeded a CA of $29.5^{\circ}$, resulting in the following exclusion distribution $(2017=\mathrm{n} 5 ; 2018=\mathrm{n} 5 ; 2019$ $=\mathrm{n} 2)$.

The mean mesio-distal CA for the test samples $(n=75)$ was $15.380 \pm 6.680$, ranging between 4.320 and 28.830 . Analysis of variance (ANOVA), revealed a significant cohort effect (based on the different years of study) on the mesiodistal convergence at the $\mathrm{p}<0.05$ level for the three cohorts
$[F(2,72)=5.28, p=0.007]$. Post hoc comparisons using the Tukey HSD test indicated that the mean CA score for the 2019 cohort at $12.02^{\circ} \pm 5.86^{\circ}$ was significantly different from the 2017 , which was $16.87^{\circ} \pm 6.94^{\circ}$ and 2018 cohorts at $17.23^{\circ} \pm 6.13^{\circ}$. There was no significant difference in CA between the 2017 and 2018 cohorts. However, a significant improvement in the mean CA of the 2019 cohort was noted when compared to the 2017 and 2018 cohorts. (Table I.) Twenty-five students achieved the ideal convergence of $12^{\circ}$ or less, of which 5 (6.6\%) achieved the ideal levels of $6^{\circ}$. Based on the three recommendations, ${ }^{3,13,14}$ on average more than $40 \%$ of the preparations satisfied the requisite range. ${ }^{16}$

\begin{tabular}{|lllllr|}
\hline \multicolumn{3}{|l}{ Table I: Summary of CA results } \\
\hline Cohort & $\mathrm{n}$ & Minimum & $\begin{array}{c}\text { Maxi- } \\
\text { mum }\end{array}$ & Mean & SD \\
\hline 2017 & 25 & $5.17^{\circ}$ & $28.16^{\circ}$ & $16.87^{\circ}$ & $\pm 6.94^{\circ}$ \\
2018 & 25 & $4.32^{\circ}$ & $27.27^{\circ}$ & $17.23^{\circ}$ & $\pm 6.13^{\circ}$ \\
2019 & 25 & $5.05^{\circ}$ & $26.54^{\circ}$ & $12.02^{\circ}$ & $\pm 5.86^{\circ}$ \\
Total & 75 & $4.32^{\circ}$ & $28.16^{\circ}$ & $15.38^{\circ}$ & $\pm 6.68^{\circ}$ \\
\hline
\end{tabular}

\section{Reliability}

Interclass correlation coefficient (ICC) estimates and their 95\% confident intervals were calculated using SPSS statistical package version 27 (SPSS Inc, Chicago, IL), based on a single-measurement by two independent researchers, absolute-agreement, 2-way mixed-effects model. The ICC $=0.996$ with $95 \%$ confidence interval $=0.981-0.999$ is indicative of excellent reliability. ${ }^{17}$

\section{DISCUSSION}

The convergence angle defines the opposing axial wall taper of a crown preparation and is one of the many factors that directly affects the overall acceptability of a crown preparation. ${ }^{18}$ Optimising axial wall taper for FCR

Figure 3: Diagrammatic representation of convergence angle $\mathbf{x}$. The enlarged infographic illustrates the calculation of angle b1 and c1 which was determined using the Image ${ }^{\circledR}$

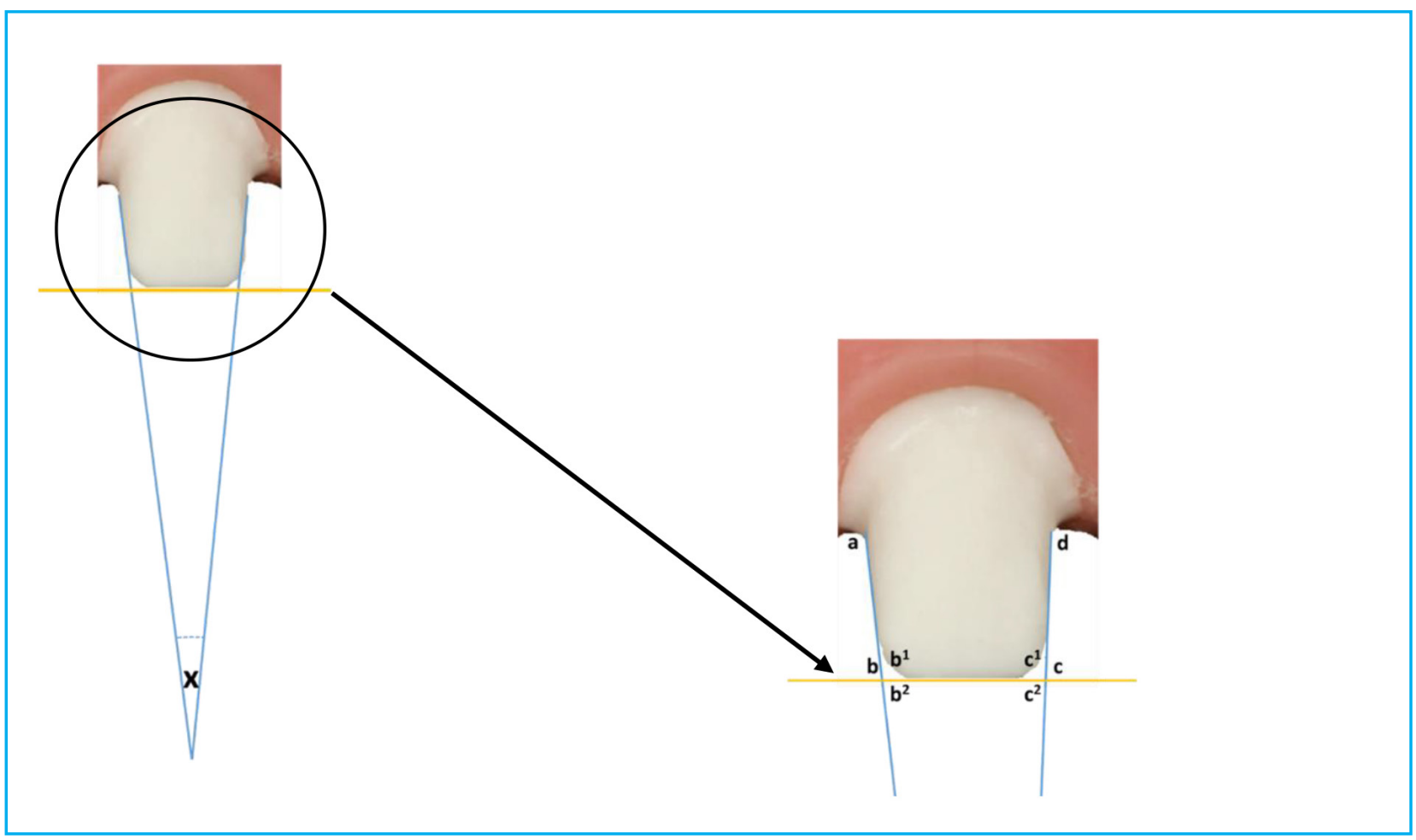




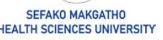

assists in achieving conservative tooth preparations' whilst simultaneously preventing undercut formation, compensating for inaccuracies in fabrication and permitting more accurate seating during cementation. , $^{6} 19$

The results of this study yielded a mean CA of $15.38^{\circ} \pm$ $6.68^{\circ}$ achieved by the fourth-year dental students' across three years of the study. The results also showed that 33\% $(n=25)$ of the combined cohorts achieved a CA between $6^{\circ}-12^{\circ}$. This finding may be attributed to adherence to minimally invasive crown preparation techniques taught, as well as, the use of only parallel-sided burs in the Fixed Prosthodontics Pre-clinical module.

The literature on CA demonstrates inconsistency in the degree of taper required for maximum retention of FCR from proposed theoretical norms when compared to clinically achieved CA. Jørgensen ${ }^{11}$ used machined brass caps to demonstrate the relationship between retention and convergence angle in cemented crowns and found that, maximal tensile retentive values were recorded at $5^{\circ}$, supporting theoretical recommendations. Kaufman et $a^{12}$ examined the effects that varying convergence angles $\left(1^{\circ}\right.$, $5^{\circ}, 10^{\circ} 15^{\circ}, 20^{\circ}$ ) would have on the retention of full coverage crowns. Their results have experimentally demonstrated that retention increases as the convergence angle decreases. Wilson and Chan ${ }^{6}$ recommended total occlusal convergence angles of between $10^{\circ}-20^{\circ}$. They based this on the fact that, these angles are achievable in a pre-clinical setting and during clinical tooth reduction. These CA should provide adequate resistance against dislodgement of restorations when coupled with other tooth preparation guidelines. ${ }^{6}$

A theoretical and clinical investigation of taper by Mack $^{14}$ showed in laboratory observations that a minimum taper of $5^{\circ}$ would need to be achieved to ensure the absence of undercuts during preparation, which supported proposed theoretical CA recommendations. However, on clinical investigation a mean $\mathrm{CA}$ of $22^{\circ}$ was achieved, showing no correlation to theoretical recommendations. He concluded that both the theory and practice recommended tapers of $5^{\circ}$ are difficult to achieve clinically. ${ }^{14}$

The lack of operator experience is often cited as common reason used to explain why undergraduate dental students over-taper teeth preparations. ${ }^{20,21}$ Annerstedt et al. ${ }^{20}$ assessed CA values of full crown preparations done on anterior, premolars and molar teeth produced by both dental students and general practitioners. However, their investigation found an average CA value of $21^{\circ}$ across all preparations types by both dental students and practitioners with no correlation to experience between the two groups. ${ }^{20}$ Their study was corroborated by a later study conducted by Patel et al, ${ }^{21}$ which established only a $1^{\circ}$ difference between the mean mesio-distal CA of final year dental students when compared to general dental practitioners. Similar earlier clinical studies by done by Leempoel et $a^{/ 22}$ and Nordlander et $a^{23}$ which assessed the CA produced by dentists with differing levels of experience, as well as, training and qualified prosthodontists. These two studies reported a mean CA for tooth preparations that ranged from $12.2^{\circ}$ to $20.1^{\circ}$ with no apparent correlation to the clinicians' level of education and/ or their experience. ${ }^{22} 23$

Nordlander et $a{ }^{23}$ study further showed that ideal preparation taper is seldom clinically achieved. A review article by Goodacre et $a^{24}$ that set to identify scientific guidelines for tooth preparations concluded that teeth should exhibit a convergence angle between $10^{\circ}-20^{\circ}$.

Currently a significant variation exists within the literature on the methods employed to calculate convergence angles due to the lack of a standardised research model. ${ }^{25}$ Studies assessing CA used a variety of methods to measure axial wall taper and CA. These methods include calibrated photography with projection of dies 22,26 projected silhouette tracings, ${ }^{21,23,27}$ microscopic photography, ${ }^{18} 3 \mathrm{D}$ laser scanning ${ }^{28}$ and 3D CAD optical imaging. ${ }^{13}$

In this study, 3D CAD image acquisition was utilised for its high degree of trueness and precision in dimensional replication of the individual tooth preparations. ${ }^{29} \mathrm{~A}$ recent study by Emir and Ayyildiz ${ }^{29}$ evaluated the trueness and precision of the Sirona inEos $X 5^{\circledR}$ and found a trueness accuracy of $26.1 \mu \mathrm{m} \pm 2.63 \mu \mathrm{m}$ and precision accuracy of $26.1 \mu \mathrm{m} \pm 1.94 \mu \mathrm{m}$. This shows that the scanner has high accuracy in dimensional replication of the scanned object. Following image acquisition, an angle analysis from the standardised labial view of each preparation using the Image $\mathrm{J}^{\circledR}$ software was done for each specimen. This analysis software was utilised due to its accessibility, reliability, ease of use and its potential as a valuable educational tool. This was validated by an inter and intra reliability confidence interval of $=0.981-0.999$.

An additional finding in the study was the reduction of the mean CA $\left(12.02^{\circ}\right)$ in the 2019 cohort, compared to the previous cohorts. A plausible inference for this improvement may be the introduction of magnified intra-oral crown preparation demonstrations. This was conducted using a dental microscope. This differed from the 2017 and 2018 cohorts, as previous demonstrations were recorded on a video recorder without such a high degree of magnification as offered by the use of a microscope. Recordings of the preparation procedure were accessible to students via the blended learning platform Blackboard ${ }^{\circledR}$. This finding is supported by an investigation conducted by Robinson and Lee ${ }^{30}$ into the use of magnification in pre-clinical teaching of crown preparations for undergraduate students. Their study showed that undergraduates produced more accurately tapered preparations using microscope video magnification as a demonstration and teaching aid, compared to students taught via conventional methods i.e. without magnification. They concluded that the use of magnification improved the undergraduates' understanding of taper preparation by enhancing their ability to visualise and evaluate this critical measurement during the teaching process. ${ }^{30}$

\section{CONCLUSION}

Objective assessment of convergence angles produced by the cohorts of 3 different years of undergraduate students demonstrated that the majority of the students were able to produce CA within recommended guidelines. A significant difference in reduction of CA was found in the 2019 cohort of students when compared to the two previous cohorts. This may be attributed to enhanced teaching and training aids. However, further investigation is required to more definitively support this assertion. With the development of more accurate technological tools to enhance the teaching of dental procedures, it is envisioned that dental schools will adopt such technologies in order to enhance and aid the 
teaching, training and learning of dental procedures, which would serve to improve on the quality of dental care that is administered by future dental practitioners.

\section{ACKNOWLEDGEMENT}

The authors wish to acknowledge and express gratitude to ARM Essop for his contribution during the concept development and measurement of the Convergence Angles stages.

\section{Disclosure}

The authors declare no conflict of interest. The article was submitted as part of the requirement for an MDent programme.

\section{References}

1. Smith CT, Gary JJ, Conkin JE, Franks HL. Effective taper criterion for the full veneer crown preparation in preclinical prosthodontics. Journal of Prosthodontics. 1999;8(3):196200.

2. Dodge W, Weed R, Baez R, Buchanan R. The effect of convergence angle on retention and resistance form. Quintessence international. 1985;16(3):191-4.

3. Ferro K, Morgano S. The Glossary of Prosthodontic Terms; Edition Nine. J prosthet dent. 2017;117(5S):16-92.

4. Shillingburg $H$, Sather D, Wilson Jr E, Cain J, Mitchel D, Blanco L. Fundamentals of fixed prosthodontics 4th Ed. Chicago. Quintessence. 2012;119(130):299-345.

5. Rosensteil S, Land M, Fujimoto J. Contemporary Fixed Prosthodontics 4th ed St louis. Mosby; 2006.

6. Wilson Jr AH, Chan DC. The relationship between preparation convergence and retention of extracoronal retainers. Journal of Prosthodontics. 1994;3(2):74-8.

7. El-Ebrashi MK, Craig RG, Peyton FA. Experimental stress analysis of dental restorations. Part III. The concept of the geometry of proximal margins. The Journal of prosthetic dentistry. 1969;22(3):333-45.

8. Saunders W, Saunders E. Prevalence of periradicular periodontitis associated with crowned teeth in an adult Scottish subpopulation. British dental journal. 1998;185(3):137-40.

9. Blair F, Wassell R, Steele J. Crowns and other extracoronal restorations: Preparations for full veneer crowns. British dental journal. 2002;192(10):561-71.

10. Malone WF, Tylman SD, Koth DL. Tylman's theory and practice of fixed prosthodontics: Ishiyaku EuroAmerica, Incorporated; 1989.

11. Jørgensen $\mathrm{K}$. The relation between retention and angle of convergence in cemented veneer crowns. Tandlaegebladet. 1955;59(2):94-8.

12. Kaufman EG, Coelho DH, Colin L. Factors influencing the retention of cemented gold castings. The Journal of Prosthetic Dentistry. 1961;11(3):487-502.

13. Marghalani TY. Convergence angles of metal ceramic crowns prepared by dental students. The Journal of prosthetic dentistry. 2014;112(5):1250-6.

14. Mack PJ. A theoretical and clinical investigation into the taper achieved on crown and inlay preparations. Journal of Oral Rehabilitation. 1980;7(3):255-65.

15. Aleisa K, Al-Dwairi ZN, Alwazzan K, Al-Moither M, Al-Shammari M, Lynch E. Convergence angles of clinical tooth preparations achieved by dental students at King Saud University, Saudi Arabia. Journal of dental education. 2013;77(9):1154-8.
16. Abdulla F, Khamis $H$, Milosevic A, Abuzayda $M$. Convergence angles of all-ceramic full crown preparations performed in Dubai private practice. Journal of clinical and experimental dentistry. 2018;10(12):e1192.

17. Bobak CA, Barr PJ, O'Malley AJ. Estimation of an interrater intra-class correlation coefficient that overcomes common assumption violations in the assessment of health measurement scales. BMC medical research methodology. 2018;18(1):1-11.

18. Ayad MF, Maghrabi AA, Rosenstiel SF. Assessment of convergence angles of tooth preparations for complete crowns among dental students. Journal of Dentistry. 2005;33(8):633-8.

19. Wiskott HA, Nicholls Jl, Belser UC. The relationship between abutment taper and resistance of cemented crowns to dynamic loading. International journal of Prosthodontics. 1996;9(2).

20. Annerstedt $A L$, Engström $U$, Hansson $A$, Jansson $T$, Karlsson S, Liljhagen $\mathrm{H}$, et al. Axial wall convergence of full veneer crown preparations Documented for dental students and general practitioners. Acta Odontologica Scandinavica. 1996;54(2):109-12.

21. Patel PB, Wildgoose DG, Winstanley RB. Comparison of convergence angles achieved in posterior teeth prepared for full veneer crowns. European Journal of Prosthodontics and Restorative Dentistry. 2005;13(3):100.

22. Leempoel $P$, Lemmens $P L$, Snoek P, Van't Hof M. The convergence angle of tooth preparations for complete crowns. The Journal of prosthetic dentistry. 1987;58(4):414-6.

23. Nordlander J, Weir D, Stoffer W, Ochi S. The taper of clinical preparations for fixed prosthodontics. The Journal of prosthetic dentistry. 1988;60(2):148-51.

24. Goodacre CJ, Campagni WV, Aquilino SA. Tooth preparations for complete crowns: an art form based on scientific principles. The Journal of prosthetic dentistry. 2001;85(4):363-76.

25. Virdee S, Addy L, Milward P, Lynch C. Convergence angles for full veneer crown preparation completed by undergraduate students in a dental teaching hospital. British dental journal. 2018;224(8):641-5.

26. Noonan Jr JE, Goldfogel MH. Convergence of the axial walls of full veneer crown preparations in a dental school environment. The Journal of prosthetic dentistry. 1991;66(5):706-8.

27. Sato T, Mutawa NA, Okada D, Hasegawa S. A clinical study on abutment taper and height of full cast crown preparations. Journal of medical and dental sciences. 1998;45(3):205-10.

28. Ghafoor R, Rahman M, Siddiqui AA. Comparison of convergence angle of prepared teeth for full veneer metal ceramic crowns. J Coll Physicians Surg Pak. 2011;21(1):15-8.

29. Emir F, Ayyldiz S. Evaluation of the trueness and precision of eight extraoral laboratory scanners with a complete-arch model: a three-dimensional analysis. journal of prosthodontic research. 2019;63(4):434-9.

30. Robinson $P$, Lee J. The use of real time video magnification for the pre-clinical teaching of crown preparations. British Dental Journal. 2001;190(9):50610. 